\title{
Reflexões em gotas sobre a trajetória da Pedagogia no país
}

\author{
Ana Lúcia Amaral ${ }^{1}$ \\ aamaral@pib.com.br
}

\section{Resumo}

O trabalho versa sobre a trajetória da Pedagogia no país, sobretudo nos últimos quarenta anos. Trajetória observada do ponto de vista da autora, cuja carreira, vasta e variada, esteve sempre ligada à sua condição de pedagoga. Tendo ocupado diversas posições nos âmbitos estadual e federal, a autora conviveu, ao longo dos anos, com diferentes modelos pedagógicos, vendo-os surgir, tornaremse hegemônicos e, subitamente, ante a emergência de um novo paradigma, serem sumariamente descartados. Na sucessão de propostas por que passou a Educação no país, a Pedagogia teve o seu campo teórico demonizado e invadido, nas últimas décadas, pela Sociologia e pela Ciência Política, num processo de denúncia do fracasso escolar como responsabilidade dos pedagogos. A denúncia e a consequente invasão do campo não deram conta de mudar o quadro da educação no Brasil: as teorias mencionadas falaram sobre Educação, destruíram os saberes pedagógicos, mas não souberam criar novos saberes que lhes permitissem fazer Educação...

Palavras-chave: Pedagogia; pedagogos; campos teóricos; saberes do pedagogo; saberes do professor.

1 Ph.D., professora aposentada da Faculdade de Educação da Universidade Federal de Minas Gerais - FaE/UFMG e do Curso de Pedagogia do Instituto de Educação de Minas Gerais - IEMG.

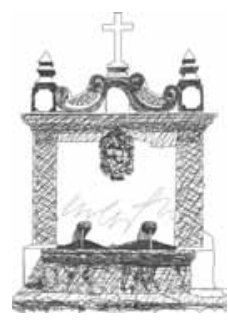

37 


\section{Gotas da minha própria trajetória}

Diplomei-me professora primária pelo Curso de Formação de Professores do Instituto de Educação de Minas Gerais (IEMG); tornei-me bacharel e licenciada em Pedagogia pela Universidade Federal de Minas Gerais (UFMG). Um pouco antes, havia me tornado supervisora escolar, tendo cursado o famoso Curso de Administração Escolar (CAE) do IEMG.

Fui professora de grupo escolar, supervisora, professora do CAE - que viria a se transformar em curso de Pedagogia em 1971, no qual exerci a docência como professora de Didática e Metodologia da Matemática, o mesmo curso que vim a dirigir no início dos anos oitenta. Fui também professora e coordenadora do Curso de Formação de Professores. Em 1985, concluí meu mestrado em educação na UFMG e em seguida fui admitida na Universidade de Stanford, Califórnia, onde, concomitantemente com o doutorado em Ciências Sociais da Educação, cursei e concluí um mestrado em Sociologia.

Retornando ao Brasil, trabalhei por mais dois anos na recémcriada Universidade do Estado de Minas Gerais (UEMG) como professora de Didática e assessora pedagógica na Reitoria do caríssimo professor Aluísio Pimenta.

Um par de anos depois, fui aprovada em concurso na FaE-UFMG, onde trabalhei como professora de Didática e pesquisadora do Grupo de Avaliação e Medidas Educacionais (GAME) e da linha de pesquisa da Pós-Graduação: " Políticas Públicas: Formulação, Implantação e Avaliação".

Longo percurso, sempre na Educação, onde sempre me senti e me identifiquei como pedagoga. Nessa trajetória, vivi variadas experiências - como aluna de grupo escolar, as fascinantes atividades da escola dita Escola Nova; como aluna de curso ginasial, as experiências típicas de um currículo enciclopédico da Escola Tradicional; como aluna do Curso de Formação de Professores, o aprendizado em profundidade dos grandes teóricos da Escola 
Nova: Montessory, Dewey, Kilpatrick, Claparède, Décroly, entre outros; como aluna do Curso de Administração Escolar do IEMG, um rico aprendizado do como ensinar: lições fantásticas sobre a unidade do fenômeno linguístico, ministradas por Lúcia Casasanta, fascinante aventura do Método da Descoberta no ensino da Matemática, as metodologias de Ciências e Estudos Sociais; na Faculdade de Educação da UFMG - FaE/UFMG, sólidos estudos teóricos de Fundamentos da Educação e Administração Escolar; no mestrado em Educação, na mesma FaE, profundos estudos embasados em teóricos tecnicistas, cujo maior expoente era, sem dúvida, Benjamin Bloom: suas Taxonomias tiveram forte influência em minha prática pedagógica, tornando-a mais lúcida e mais rica.

Embora adquirido em diferentes instituições, meu arsenal pedagógico era constituído de teoria e prática: ensinaram-me a discutir a Educação e a fazer Educação.

Professora, supervisora escolar e coordenadora de curso de formação de professores, diretora de curso de pedagogia, chefe de departamento, pesquisadora, coordenadora da Subsecretaria de Desenvolvimento Educacional da SEE, consultora de programas educacionais semipresenciais e a distância - cargos que exerci sob a égide dos diferenciados modelos pedagógicos já referidos. A cada afirmação de um novo modelo, o outro era abandonado pela academia e responsabilizado pelos sucessivos fracassos da escola brasileira. Do modelo anterior, nada permanecia.

Quando parti para o doutorado, vigia no corpo acadêmico da Educação um discurso marxista e neomarxista, subsidiado pela Sociologia e pela Ciência Política, substituindo as referências anteriores ditadas pela Filosofia, pela Psicologia e pela Economia, nessa ordem.

Quando voltei do doutorado, na década de mil novecentos e noventa, assisti à implantação, juntamente com as teorias marxistas, de outro modelo conhecido como Construtivismo, cuja ênfase acentuada no desenvolvimento da aprendizagem do aluno, acabava por minimizar o que a Pedagogia caracterizava como ensino.

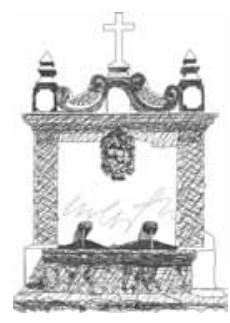




\section{Gotas da trajetória da Pedagogia no país}

O século XX assistiu ao apogeu e ao declínio da Pedagogia; melhor dizendo, ao prestígio e ao descrédito dos pedagogos...

Quero crer que o apogeu da Pedagogia em nosso país começou já na década de trinta, quando se tornou hegemônico no Brasil o pensamento escolanovista, permanecendo aproximadamente até o início dos anos sessenta, quando muda toda a configuração educacional com a instalação do Regime Militar em 1964.

Segundo Ghiraldelli (2001), após a Primeira Guerra Mundial, o Brasil começou a diversificar suas relações comerciais e financeiras, anteriormente limitadas às relações com a Inglaterra, abrindo espaço para os contatos com os Estados Unidos, não somente econômicos, mas culturais e, sobretudo, importando a produção educacional e pedagógica americana. Todo o ideário pedagógico do Movimento da Escola Nova - movimento originado na Europa, mas desenvolvido nos Estados Unidos por John Dewey e seu discípulo William Kilpatrick, chegou ao Brasil principalmente em sua versão americana.

Esse movimento enfatizava os métodos ativos de ensinoaprendizagem, a experiência e a atividade infantis, a curiosidade e a liberdade da criança, o debate e a vivência democrática na escola, o respeito aos interesses infantis e às diferenças individuais, valorizando os estudos de Pedagogia Experimental que dariam suporte a uma "Pedagogia Científica". Em notável frase, Dewey afirmava que "trata-se de uma transformação que se compara com a de Copérnico em nosso sistema planetário". Destaque-se o deslocamento do eixo da escola: do professor para a criança (AMARAL, 2008).

Vários estados brasileiros, inspirados por jovens intelectuais como o baiano Anísio Teixeira (discípulo de Dewey), Fernando de Azevedo, Lourenço Filho, Francisco Campos, entre outros, promoveram reformas educacionais inspiradas na Escola Nova.

Em Minas Gerais, mais especificamente em Belo Horizonte, 
a notória Escola de Aperfeiçoamento (que veio a se transformar no Curso de Administração Escolar) e o CAE foram, tanto um quanto o outro, cada um em seu tempo, responsáveis pela primorosa formação de especialistas educacionais (supervisores, orientadores, administradores, inspetores) que, após dois anos de cuidadoso preparo pedagógico e metodológico, retornavam a seus municípios (ou estados), responsabilizando-se pela disseminação, em suas escolas de origem, das ideias e práticas escolanovistas estudadas e vivenciadas naquele precioso biênio.

À época, o Curso de Formação de Professores, tal como o Curso de Administração Escolar, contava com o seleto grupo de professoras do Grupo Escolar anexo para ministrar aulas de demonstração das diversas disciplinas do currículo, sob a orientação das formadoras das diferentes metodologias. Entre as muitas grandes mestras, destaco a figura ímpar de Lúcia Casasanta, piagetiana convicta que nos ensinou o valor do método e das técnicas, ela própria responsável pelo aprimoramento e disseminação do Método Global de Contos, método que me iniciou no aprendizado da leitura e da escrita ("Livro de Lili"), a mim e a meus filhos ("As mais belas histórias").

Tivemos também a proveitosa experiência desenvolvida em colégios de aplicação das universidades. Professores de Educação Básica, muito bem preparados, ministravam, a seus alunos regulares, aulas previamente encomendadas pelo formador de professores dos cursos de Pedagogia, com o propósito de serem observadas e discutidas por seus alunos, sob a sua orientação.

Entretanto, num dado momento, essas aulas passaram a ser consideradas "fictícias" pelos formuladores de políticas educacionais, e uma nova política pedagógica se implantou no país, agora dirigindo os alunos para "estágios supervisionados" em escolas públicas, supostamente a "verdadeira imersão na realidade" das nossas escolas. Com um número cada vez maior de alunos e de escolas em diferentes localizações, os professores formadores não puderam mais estar presentes nas salas de aula observadas.

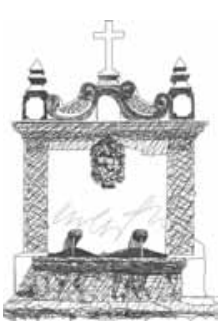


Os anos setenta foram fortemente marcados pelo Tecnicismo, pelo apelo de ordem econômica, referenciados pela Teoria do Capital Humano e assistiram à substituição da busca da qualidade pela busca da quantidade. No intuito explícito de democratização da escola pública, o sistema educacional abriu suas portas a uma nova clientela - as classes menos favorecidas - mas com o intuito implícito de escolarizar uma clientela destinada a suprir as necessidades do mercado de trabalho em franca industrialização. Havia uma ênfase excessiva no planejamento, elaborado em níveis superiores, para ser executado pelos professores em sala de aula. Esse planejamento era balizado, desde antes, até o fim do processo, pela avaliação, tendo sempre em vista o alcance dos objetivos e metas propostos. Embora tenha sido, em épocas posteriores, negativamente marcado pela associação à ditadura militar - época em que foi introduzido no Brasil - o Tecnicismo trouxe algumas contribuições valiosas à Pedagogia como, por exemplo, os estudos sobre os produtos de aprendizagem desenvolvidos por Bloom e outros estudiosos, que se concretizaram em Taxonomias nas áreas da Cognição, Psicomotricidade e Afetividade; estas duas, especialmente, ainda desconhecidas de grande parte de nossos educadores.

A aprendizagem, que no escolanovismo havia sido tratada como um atributo medido pela curva normal (a curva de Gauss, que alocava os alunos em fortes, médios e fracos), passou a ser tratada como um processo a ser inserido na curva de Bloom - rightly skewed, isto é, uma curva inclinada para a direita (de escores altos), significando que a quase totalidade dos alunos deveria chegar aos patamares mínimos de escolaridade estabelecidos. Essa "perseguição" dos padrões mínimos de qualidade era da responsabilidade do professor. Bloom introduziu ainda, na educação escolar, as importantes funções da avaliação: diagnóstica, formativa e somativa (BLOOM, HASTINGS \& MADAUS, 1971).

Com a mudança da clientela e dos objetivos dos formuladores de políticas educacionais, a Educação se revestiu de um novo caráter: para dar conta da massificação proposta, o ensino não 
podia mais se dar ao luxo de bibliotecas de classe, clubes de leitura, cantinhos de ciências, descobertas matemáticas, hortas escolares... A busca da construção da cidadania, tão necessária à vida em uma sociedade democrática - mote da Escola Nova - já não era mais possível nem necessária. Tais procedimentos deram lugar a um ensino não socializado, mas individualizado sob a forma de módulos de aprendizagem. No desconhecimento do perfil e das necessidades dos novos alunos, os professores não sabiam como agir. A massificação que se perpetrou na escola fundamental estendeu-se aos demais níveis de ensino, atingindo a formação de professores (AMARAL, 1985).

Deu-se, então, um efeito negativo em cascata: o fracasso foi tomando conta de nossas escolas e os fantasmas da repetência e da evasão escolar passaram a fazer parte da rotina escolar, agora em larga escala.

Nos anos oitenta, assistimos ao desembarque, nos "portos" educacionais brasileiros, das teorias da reproduçãoe, posteriormente, da teoria crítica. Aquele foi um momento marcado fortemente pelo viés sociológico e político, tendo como pano de fundo as teorias marxistas. Foi um momento de denúncia da discriminação social e cultural realizada pelo sistema educacional - via avaliação - que estaria fazendo com que a pirâmide educacional reproduzisse a pirâmide social. Chegou-se mesmo ao estabelecimento de comparações entre a fábrica e a escola, esta invocada como uma grande produtora do fracasso escolar, orquestrado por supervisores, orientadores, administradores e inspetores escolares, supostos agentes a serviço do capitalismo selvagem a roubarem a autonomia e a criatividade do professor, agora mero executor de tarefas planejadas em instâncias mais altas.

Tal discurso de esquerda foi apropriado pela direita e, em alguns outros estados da União, serviu de marco teórico para o início de um grande descrédito da supervisão e da orientação que, entretanto, especialmente em escolas do interior, prestavam um enorme auxílio à educação fundamental. Não estou aqui a

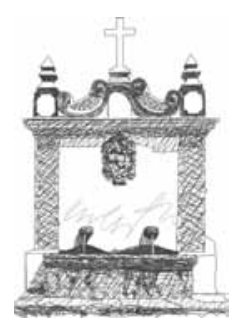


defender ou censurar o resgate das antigas habilitações do CAE e/ ou dos cursos de Pedagogia, mas não há dúvida de que aqueles profissionais, à época, eram extremamente importantes na garantia da qualidade do ensino fundamental em Minas Gerais.

Começara um discurso de ataque ao positivismo educacional e ao "pecado da aplicação", fosse de teorias ou métodos e, sobretudo, de técnicas, palavra equivocadamente associada ao Tecnicismo que acabara por elevar a técnica, esta, um meio, à condição de fim.

A Ciência passou a ser vista com desconfiança e, mais uma vez, os subsídios que nos eram dados pela Psicologia e mesmo pela Economia foram sumariamente descartados. As pesquisas de natureza micro, quais sejam, aquelas desenvolvidas no âmbito das salas de aula foram rejeitadas e o pedagogo foi usado como o bode expiatório do fracasso educacional brasileiro.

\section{Gotas de reflexão sobre a invasão do campo chamado Pedagogia}

Pièrre Bourdieu (1988) nos brindou com um detalhado estudo sobre a disputa de poder nas faculdades universitárias da França. O prestígio de cada uma delas está ligado às origens de seus professores, estas influenciando sobejamente o seu capital cultural, assim como a capacidade de cada uma das faculdades de se afirmar no campo de lutas que é a própria universidade.

Em outros trabalhos, Bourdieu (apud ORTIZ, 1983) nos fala do campo científico, conceito explorado, com muita felicidade, por Magda Soares (2000) na tentativa de explicar a tensão entre a Didática e o Currículo no campo pedagógico.

Assumo que é válida a tentativa de trazer também para este contexto o conceito de campo bourdieuniano, para explicar a luta travada entre os diferentes campos científicos ligados ao objeto Educação (Psicologia Educacional, Sociologia da Educação, Filosofia da Educação, entre outros) e a Pedagogia.

Depreendi que esses campos olhavam o fenômeno educativo 
sob a ótica do seu próprio campo teórico. Assim, a Sociologia da Educação estudava a Educação com o viés característico do campo da Sociologia e o mesmo se dava com as demais ciências. Cabia à Pedagogia valer-se desses conhecimentos para melhor compreender o fenômeno educativo em suas diferentes manifestações, melhor dizendo, em sua totalidade. A Pedagogia é a ciência da Educação por excelência.

Entretanto, à Pedagogia cabia não somente compreender a Educação, mas fazer Educação! Isso requeria fazer uso dos conhecimentos da prática já experimentados e consagrados, como também pesquisar novos conhecimentos no campo dessa mesma prática. Esse era o corpo de conhecimentos próprio da Pedagogia.

Todavia, esses saberes passaram a ser alvo de ataque ferrenho, sobretudo dos sociólogos. Num processo de autodefesa, de sobrevivência, a Pedagogia passou a absorver o discurso político e sociológico que se tornara hegemônico e a abandonar o seu próprio discurso.

Os discursos marxista e neomarxista surgiram por aqui na década de oitenta: Marx na releitura de Gramsci, Bowles e Gintis, Althusser, Bourdieu e Passeron, Baudelot e Establet, entre outros, a enfatizar o caráter reprodutivista da Educação. A Sociologia se incumbiu da disseminação do pensamento desses autores.

É mister ressaltar que, em grande parte dos cursos de Pedagogia, o saber pedagógico foi sumariamente substituído pelo saber político e sociológico. Na Faculdade de Educação da UFMG não importava a disciplina ministrada; os textos e o discurso eram sempre os mesmos ${ }^{2}$. É muito estranho pensar que eram os próprios pedagogos que se incumbiam de difundir um discurso destruidor de sua própria profissão. ${ }^{3}$

Em Minas Gerais, o Curso de Administração Escolar, alçado à

2 Ex-diretora da FaE/UFMG nos fala da constatação, à época, dessa uniformidade do discurso, concretizada nos textos recomendados pelos professores. A pós-graduação exercia, então, uma forte influência na docência e na estruturação da graduação.

3 Entretanto, renomada pedagoga do sul do país nos chama a atenção para o fato de que em faculdades de pequeno porte, no interior dos estados, o currículo da Pedagogia manteve um cunho fortemente tecnicista, mas que era, infelizmente, na maioria das vezes, de qualidade duvidosa...

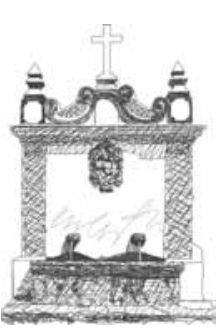


condição de curso de Pedagogia, foi, aos poucos, perdendo a sua marca de excelência pedagógica, que se traduzia numa forte carga curricular das metodologias, estas ministradas por pedagogas de renome. Além da homogeneização teórica, sua estrutura escolar também foi enormemente modificada, com as metodologias perdendo espaço para as disciplinas ditas de "fundamentação". Tornou-se um curso de Pedagogia não diferenciado.

Os pedagogos, atacados na essência de sua profissão, envergonhavam-se de sua condição de pedagogos. Os "fundamentos" da Educação que deveriam "iluminar" a teoria e a prática pedagógicas tornaram-se o cerne da Pedagogia. A prática pedagógica desapareceu, dando espaço ao discurso teórico das disciplinas de fundamentação que, ironicamente, como mencionamos, era o mesmo, qualquer que fosse a disciplina ministrada. Na guerra dos "campos científicos" a Pedagogia abriu mão de seu espaço de práxis da Educação para teorias que o invadiram, permanecendo no campo da denúncia, sem condições de fazerem Educação.

Num processo similar, sem embasamento teórico para mudar o quadro dominante, os pedagogos foram aos poucos se transformando em pseudofilósofos, pseudopsicólogos, pseudossociólogos etc., a repetir o jargão dos outros campos, mas sem o estofo necessário para teorizar sobre eles, confrontando-os (AMARAL, 2010). Pedagogos que ostentavam o orgulho da denúncia das mazelas da escola, mas sem a coragem necessária para atravessar os seus portões para saneá-las, em seu verdadeiro papel...

\section{Gotas de ansiedade sobre o futuro da Pedagogia}

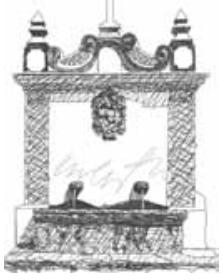

Na atualidade, estamos vivendo, legalmente, sob as determinações das Diretrizes Curriculares Nacionais para o Curso de Graduação em Pedagogia, Licenciatura, estabelecidas em 2006 (CONSELHO NACIONAL DE EDUCAÇÃO, 2006). Nos meios acadêmicos, a ausência de consenso sobre a identidade da Pedagogia: formação de pedagogos ou formação de professores? Ou os dois? 
Qualquer que seja o rumo a tomar, é mister que se definam, sem medo, os saberes necessários à sua formação.

Se a opção for pela formação do especialista em Pedagogia, é preciso que o pedagogo assuma, sem medo, a especialidade escolhida. Mas há que mergulhar a fundo nos saberes já consagrados pela pesquisa pedagógica (não há necessidade de reinventar a roda a todo momento) e realizar novas pesquisas no campo, de modo a desenvolver conhecimentos teóricos e práticos, tanto no âmbito pedagógico em geral quanto no âmbito específico de sua comunidade escolar.

O pedagogo deve, sim, valer-se das contribuições da Filosofia, da História da Educação, da Antropologia, da Sociologia, da Psicologia, da Ciência Política, da Economia, dos estudos ambientais e ecológicos, da Administração, mas fazendo desses conhecimentos um amálgama que possa dar sustentação aos saberes que lhe são próprios.

As Diretrizes Curriculares, mesmo enfatizando a docência na formação do pedagogo, sugere inúmeras competências que o curso de Pedagogia deve propiciar ao pedagogo, em sua formação mais ampla.

Se, entretanto, a opção for pela docência, vale a pena relembrar que um bom número de autores já classificou, com algumas variações, os saberes que deveriam ser do domínio do professor: Perrenoud, Altet, Tardif, entre muitos. Tenho particular apreço pela classificação de Clermont Gauthier (1998). Ele os classifica como: (i) saber disciplinar - se refere ao conhecimento produzido pelos pesquisadores e cientistas nas diversas disciplinas científicas; (ii) saber curricular - uma disciplina nunca é ensinada tal qual; na verdade, ela sofre inúmeras transformações para se tornar um programa de ensino; (iii) saber das ciências da educação - os professores adquirem, durante a sua formação ou em seu trabalho, determinados conhecimentos profissionais que "permeiam a maneira de o professor existir profissionalmente" e que, embora não os ajudem diretamente a ensinar, apresentam-lhes

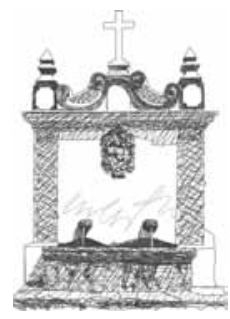


determinadas facetas de seu ofício ou da educação em geral; (iv) saber da tradição pedagógica - um saber que transparece numa espécie de intervalo da consciência. Cada professor tem uma representação da escola, que o determina antes mesmo de ter feito um curso de formação de professores; (v) saber experiencial - a experiência e o hábito estão intimamente relacionados. Aprender por meio de suas próprias experiências significa viver um momento particular, momento esse diferente de tudo o que se encontra habitualmente sendo registrado como tal em nosso repertório de saberes. A experiência torna-se a regra e pode assumir a forma de rotina. $\mathrm{O}$ professor elabora uma jurisprudência particular feita de truques que ele acredita que funcionam; e, finalmente, (vi) o saber da ação pedagógica - que é o saber experiencial dos professores, a partir do momento em que se torna público e que é testado por meio das pesquisas realizadas em sala de aula. Os saberes da ação pedagógica legitimados pelas pesquisas são atualmente o tipo de saber menos desenvolvido no repertório de saberes do professor, embora seja, paradoxalmente, o mais necessário à profissionalização do ensino.

Gauthier (1998) argumenta que, na falta de um saber da ação pedagógica válido, o professor, para fundamentar seus gestos, continuará recorrendo à experiência, à tradição, ao bom senso, saberes que, além de comportarem limitações importantes, não o distinguem em nada, ou quase em nada, do cidadão comum.

Vemos, assim, que fica permitido ao professor o uso do ensaio e erro com seus alunos. E me pergunto: onde fica a ética do ensinar em situações como essa? Quando precisamos de um médico, um dentista ou um psicólogo para nossos filhos, procuramos informações a respeito dos profissionais, buscamos o que há de melhor, mas contentamo-nos em entregá-los a um processo de ensaio e erro quando se trata de sua educação.

Gauthier (1998) pondera ainda que, para profissionalizar o ensino, é essencial identificar saberes da ação pedagógica válidos e levar os outros atores sociais a aceitar a pertinência desses saberes. 
Mas como convencer a sociedade da pertinência desses saberes se os próprios docentes não se convenceram dela?

Além dos saberes necessários à formação de bons professores, não podemos nos esquecer de que o ideário pedagógico brasileiro recebeu, nas últimas décadas, a influência de alguns pensadores estrangeiros voltados para a questão da prática. Destaco, entre eles, o americano Donald Schön, que se inspirou nos escritos de John Dewey para desenvolver um trabalho que centra sua concepção de desenvolvimento de uma prática reflexiva em três ideias centrais: "o conhecimento na ação, a reflexão na ação e a reflexão sobre a reflexão na ação" (SCHÖN, 2000).

A concepção de profissional reflexivo elaborada por Schön pretendia, sobretudo, capacitar o profissional (em nosso caso, o professor) para lidar com as "incertezas" da prática. Não podemos nos esquecer, entretanto, de que uma boa formação inicial é aquela que reduz sobremaneira o leque de incertezas da prática. Uma boa formação profissional é aquela que procura garantir a aquisição de "equipamentos" (saberes) necessários à atuação eficiente do professor. É ela que permite ao professor chegar a seu campo de trabalho e enfrentar os desafios da prática com mais segurança, sem necessariamente se entregar a um processo de ensaio e erro, já mencionado, cujas chances de fracasso se sobrepõem às de sucesso.

Entretanto, o conceito de reflexão que acabou dando origem ao que se consagrou como a epistemologia da prática incomodou e ainda vem incomodando muitos educadores (AMARAL, 2002; PIMENTA, 2002). Vejamos:

[...] o saber docente não é formado apenas da prática, sendo também nutrido pelas teorias da educação. Dessa forma, a teoria tem importância fundamental na formação dos docentes, pois dota os sujeitos de variados pontos de vista para uma ação contextualizada, oferecendo perspectivas de análise para que os professores compreendam os contextos históricos, sociais, culturais, organizacionais e de si próprios como profissionais (PIMENTA, 2002, p. 24).

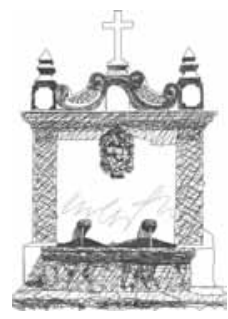


Assim, não se pode refletir nem analisar a própria prática ou a de outrem sem uma sólida base teórica, sem o que corremos o risco de permanecer no que Gauthier chamou de saber experiencial, aprendendo por meio das próprias experiências o que significa viver um momento particular, que leva o professor a elaborar uma jurisprudência particular feita de truques que ele acredita que funcionam...

\section{Conclusão em gotas...}

- A Pedagogia é a ciência da Educação.

- Embora embasada em grande número de outras ciências, que enxergam a Educação pelo viés de seu corpo teórico, é ela que tem a visão de totalidade do fenômeno educativo.

- Para ter essa visão de totalidade, a Pedagogia não pode se valer apenas dos fundamentos das outras ciências que a compõem; ela precisa consolidar e expandir as suas próprias pesquisas.

- Como cientistas da Educação, os pedagogos não podem se limitar a ter uma visão de totalidade do fenômeno educativo; além de enxergar o fenômeno, eles têm de nele intervir: não apenas olhar a Educação, refletir sobre ela, mas, sobretudo, fazer Educação.

- Para fazer educação, é preciso adentrar o universo da escola básica: unir escola e universidade!

- Para ganhar espaço e prestígio no campo universitário, os pedagogos precisam se convencer de que, se o futuro de uma nação está, incontestavelmente, ligado à qualidade de sua educação, o futuro do nosso país está, incontestavelmente, ligado à qualidade de seus pedagogos, sejam eles especialistas ou professores, ou ambos.

- Para ganhar espaço e prestígio junto a outros profissionais e junto à sociedade, é preciso que o pedagogo acredite em si mesmo e no seu trabalho. Se não está convencido do seu valor, como convencer a outros?

- Para ganhar espaço e prestígio junto a outros profissionais e 
junto à sociedade, é preciso que os cursos de Pedagogia ofereçam aos pedagogos, verdadeiramente, ensino de qualidade.

- Para que a Pedagogia possa realmente trabalhar por ensino de qualidade, é preciso que seus saberes sejam tanto teóricos quanto práticos (ressalte-se a necessidade de estágios efetivos).

- Para ganhar espaço e prestígio junto a outros campos e junto à sociedade, é preciso que a Pedagogia atraia para si os melhores candidatos nos processos seletivos.

- Para ganhar espaço e prestígio, os pedagogos precisam batalhar por uma carreira claramente definida, melhores salários e melhores condições de trabalho.

- Para que esse ciclo se feche, é preciso, sobretudo, que o pedagogo tenha orgulho de ser pedagogo!!!

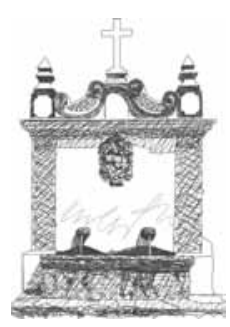




\title{
Referências
}

\begin{abstract}
AMARAL, A. L. A pseudo-democratização da Escola Normal. Um estudo no Instituto de Educação de Minas Gerais. 1985. Dissertação (Mestrado em Educação - área de Concentração Metodologia de Ensino). Faculdade de Educação da Universidade Federal de Minas Gerais - FaE/UFMG, Belo Horizonte, 1985.
\end{abstract}

A adjetivação do professor: uma identidade perdida? In: VEIGA, I. P. A. e AMARAL, A. L. (Orgs.) Formação de professores: políticas e debates. Campinas, SP: Papirus, 2002. p. 131-154.

Avaliação Educacional em Minas Gerais nas décadas de 1920 a 1950. In: DALBEN, A. I. L. de F. (Org.). Avaliação Educacional. Memórias, trajetórias e propostas. Belo Horizonte: Editora UFMG, 2008. p. 84-106.

Significados e contradições nos processos de formação de professores. In: DALBEN et al. (Orgs.) Convergências e tensões no campo da formação e do trabalho docente. XV Endipe. Belo Horizonte: Autêntica, 2010. p. 24-46.

BLOOM, HASTINGS \& MADAUS. Handbook on Formative and Summative Evaluation of Student Learning. New York: McGrawHill, 1971.

BOURDIEU, P. O campo científico. In: ORTIZ, R. (Org.). Pièrre Bourdieu: Sociologia. São Paulo: Ática, 1983. . Homo Academicus. Stanford, CA: Stanford University Press, 1988. 
CONSELHO NACIONAL de EDUCAÇÃO. Conselho Pleno.

Resolução CNE/CP n. 1, de 15 de maio de 2006. Institui Diretrizes

Curriculares Nacionais para o curso de graduação em

Pedagogia. Disponível em: <http:/ /www.mec.gov.br>.

GAUTHIER, C. et al. Por uma Teoria da Pedagogia. Pesquisas

Contemporâneas sobre o Saber Docente. Ijuí: Unijuí, 1998.

GHIRALDELLI JR., P. História da Educação. São Paulo: Cortez, 2001.

PIMENTA, S. G. Professor Reflexivo: construindo uma crítica. In: PIMENTA; GHEDIN (Orgs.) Professor Reflexivo no Brasil: gênese e crítica de um conceito. São Paulo: Cortez, 2002. p. 17-52.

SCHÖN, D. Educando o Profissional Reflexivo: um novo design para o ensino e a aprendizagem. Porto Alegre: Artmed, 2000.

SOARES, M. B. Trabalho apresentado em Mesa Redonda do X ENDIPE, UERJ, Rio de Janeiro, 2000. (mimeo).

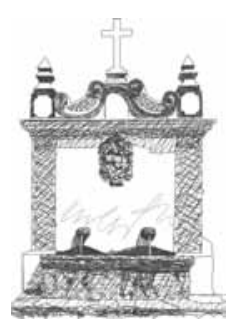




\title{
Drops of reflections on the Pedagogy trajectory in this country
}

\begin{abstract}
:
This paper deals with the Pedagogy trajectory in Brazil, moreover in the last forty years, viewed from the perspective of the author, whose extensive and diversified career was always connected to her condition of a pedagogue. Having occupied different positions in state and federal levels, the author performed under different pedagogical models, seeing them emerge, gain hegemony and, facing the appearance of a new paradigm, be summarily discharged. Facing a large number of educational proposals, Pedagogy had demonized its theoretical field, also invaded in the last decades by Sociology and Political Science, in a process of accusation of pedagogues as those responsible for schooling failure. Accusation and consequent invasion of the Pedagogy field were not enough to change the picture of Education in the country: the theories mentioned talked about Education, destructing pedagogical knowledge, but were not able to create a new knowledge that allowed them to do Education.
\end{abstract}

Keywords: Pedagogy; pedagogues; theoretical fields; pedagogue's knowledge; teacher's knowledge. 